\title{
Universal mobile protection system for aerosol-generating medical interventions in COVID-19 patients
}

\author{
Florian Straube ${ }^{1,2^{*}} \mathbb{D}$, Clemens Wendtner ${ }^{3}$, Ellen Hoffmann ${ }^{1,2}$ and Munich Clinic Collaboration Group
}

Keywords: Aerosol-generation medical interventions, Healthcare personnel, High-flow nasal cannula oxygen, Noninvasive ventilation, COVID-19, SARS-CoV-2, Virus transmission, Protection gear, Shield

\section{Refers to:}

Huang L, Lin G, Tang L, Yu L, Zhou Z. Special attention to nurses' protection during the COVID-19 epidemic. Crit Care. 2020;24(1):120.

SARS-CoV-2 can actively replicate in the upper respiratory tract and is shed for a prolonged time after symptoms end [1]. The prolonged viral shedding in sputum is relevant for hospital infection control [1]. Hospital-related transmission of the virus is a large threat to healthcare workers [2] especially if COVID-19 patients are treated by non-invasive ventilation or highflow nasal oxygen [3].

Leonard et al. have recently proposed to use a surgical mask for the patient treated by high-flow nasal oxygen. At $40 \mathrm{~L} \times \mathrm{min}^{-1}$, the surgical mask captured $83.2 \%$ of particles [3]. It remains unclear if this is effective with increased flow velocities, and it does not apply to many aerosol-generating medical interventions.

For healthcare workers performing aerosol-generating procedures on patients with COVID-19, using fitted respirator masks (e.g., N95 respirators) in addition to other personal protective equipment (i.e., gloves, gown, eye protection, such as a face shield or goggles) has been

\footnotetext{
* Correspondence: florian.straube@muenchen-klinik.de

'Department of Cardiology and Internal Intensive Care Medicine, Munich Clinic Bogenhausen, Academic Teaching Hospital, Technical University of Munich (TUM), Englschalkinger Str. 77, 81925 Munich, Germany ${ }^{2}$ Department of Cardiology, Pneumology and Internal Intensive Care Medicine, Munich Clinic Schwabing, Academic Teaching Hospital, Ludwig-Maximilians-University (LMU), Munich, Germany

Full list of author information is available at the end of the article
}

recommended [4]. This equipment is mainly based on disposable materials, and the supply is limited in the context of the pandemic [5].

A new mobile and reusable protection system has been established. Medical staff might use it in addition to the personal protection measures already in operation.

The construction (Fig. 1) is made of a commercially available and easy to process opaque aluminum composite panel (bottom) on swivel castors and a transparent acrylic glass (top). A detailed description is available (DOI https://doi.org/10.31219/osf.io/2s93d; https://osf. io/2s93d/).

Unique features of the system are as follows: protective equipment neither worn by staff nor patients, but is placed on the ground and can be moved around on castors; flexible system for confined spaces, in operating rooms or functional areas; the transparent protective screen with an angled field of vision; and side shields deflect and prevent aerosols to be inhaled by the user. Openings allow personnel to treat patients without significantly reducing the shielding effect. The shielding has been visualized by steam tests (videos are provided online https://osf.io/7u2tv).

It might be used in addition to established protection measures for aerosol-generating procedures, e.g., for patient care during high-flow or non-invasive ventilation therapy, in-/extubation, upper GI endoscopy, bronchoscopy, transesophageal echocardiography, or drainage.

In those times, disposable protection gear is scarce, and the robust, easy-to-disinfect, reusable, mobile 


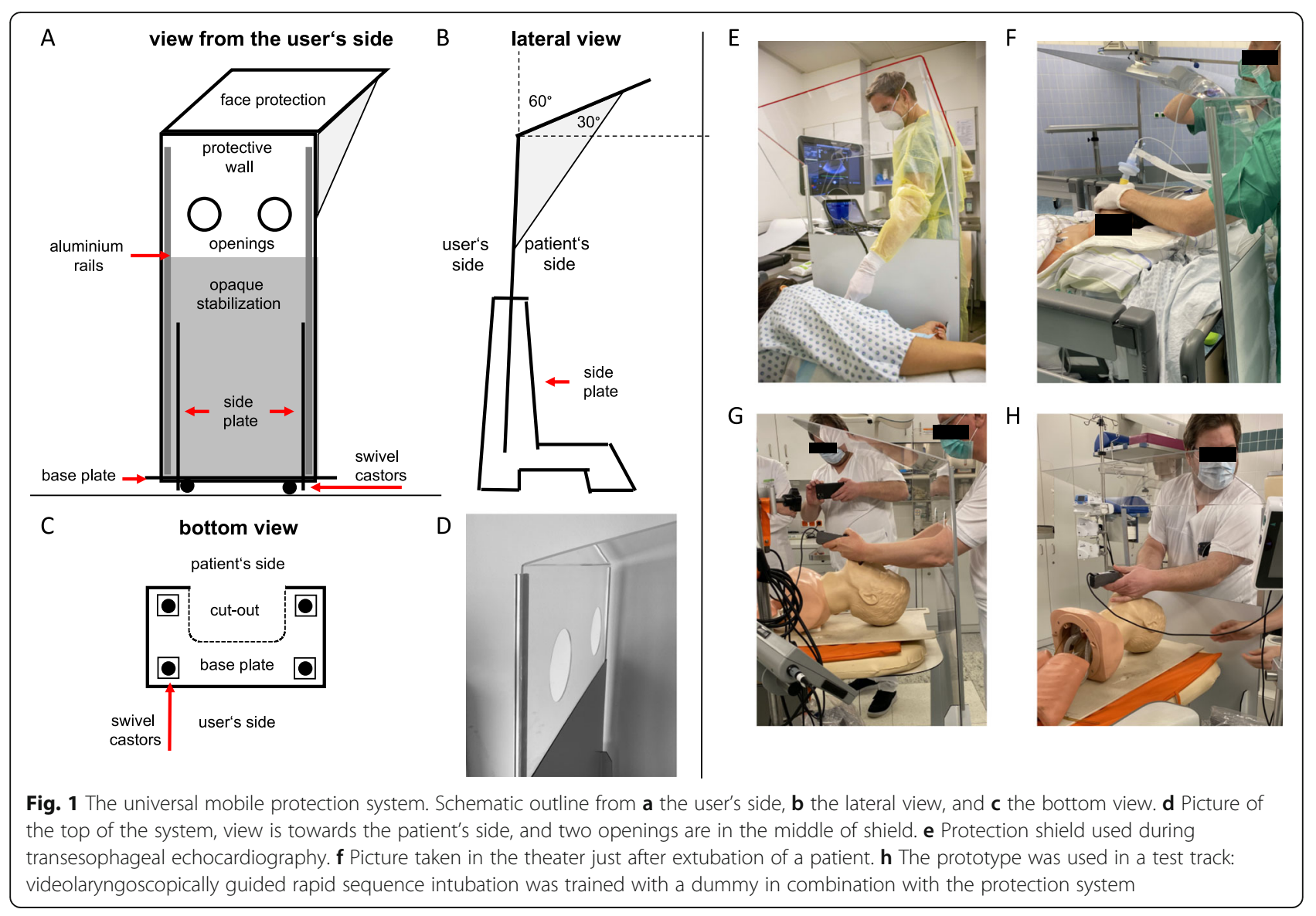

protection system might be helpful for medical personnel to work more safely in vulnerable situations. The universal, mobile protection system was evaluated in a test track and is considered useful by the main medical disciplines involved in the treatment of COVID-19 patients.

\section{Abbreviations}

COVID-19: Corona virus disease 2019; N95: A medical mask meeting the N95 National Institute for Occupational Safety and Health air filtration rating (USA); SARS-CoV-2: Severe acute respiratory syndrome coronavirus 2

\section{Acknowledgements}

This project was set up in a collaboration with the team of the Munich Clinic Bogenhausen and Schwabing. The following collaborators contributed to this project: Munich Clinic Collaboration Group: Volz S. ', Dorwarth U.', Engel M. ${ }^{1}$, Schneider N. ${ }^{2}$, Lärmer J. ${ }^{2}$, Nagel B. ${ }^{2}$, Friederich P. ${ }^{4}$, Fisch R. ${ }^{4}$, Riess A. ${ }^{4}$, Benedikter J. ${ }^{5}$, Meyer F.J. ${ }^{5,6}$, Lewerenz B. ${ }^{7}$, Schepp W. ${ }^{7}$, Schmid M. ${ }^{8}$, Dodt C. ${ }^{8}$, Schmidt W. ${ }^{1}$, Weidenbach K. ${ }^{1}$, Rogowski S. ${ }^{1}$, Kossmann H. ${ }^{1}$, Berger M. ${ }^{1}$, Gatos C. ${ }^{1}$, Wuerstl B. ${ }^{9}$, and Deichstetter M. ${ }^{1}$

Special thanks go to Kevin Thuma und Halil Sayar, and the team of Matthias Wenzel (Wenzel GmbH, Munich, Germany) who advanced the project with great enthusiasm and precision in the phase of technical implementation and development of the prototype.

Dipl.-Ing. Rene Gross (Munich, Germany) gave technical advice in the area of material science. Many thanks to the cath lab personnel who helped with the gradual disinfection exposure tests.

'Department of Cardiology and Internal Intensive Care Medicine, Munich Clinic Bogenhausen, Academic Teaching Hospital, Technical University of Munich (TUM), Munich, Germany
${ }^{2}$ Department of Cardiology, Pneumology and Internal Intensive Care Medicine, Munich Clinic Schwabing, Academic Teaching Hospital, LudwigMaximilians-University (LMU), Munich, Germany

${ }^{3}$ Department of Hematology, Oncology, Immunology, Palliative Medicine, Infectious Diseases and Tropical Medicine, Munich Clinic Schwabing, Academic Teaching Hospital (LMU), Kölner Platz 1, 80804 Munich, Germany ${ }^{4}$ Department of Anaesthesiology, Munich Clinic Bogenhausen, Academic Teaching Hospital (TUM), Munich, Germany

${ }^{5}$ Department of Pulmonology and Pneumological Oncology, Munich Clinic Bogenhausen, Academic Teaching Hospital (TUM), Munich, Germany

${ }^{6}$ Department of Pulmonology, Gastroenterology and Internal Intensive Care Medicine, Munich Clinic Harlaching, Academic Teaching Hospital (LMU),

Munich, Germany

${ }^{7}$ Department of Gastroenterology, Hepatology and Gastrointestinal Oncology, Munich Clinic Bogenhausen, Academic Teaching Hospital (TUM), Munich, Germany

${ }^{8}$ Department of Emergency Medicine, Munich Clinic Bogenhausen, Academic Teaching Hospital (TUM), Munich, Germany

${ }^{9}$ Department of Hygiene and Prevention of Infectious Diseases, Munich Clinic Schwabing, Academic Teaching Hospital (LMU), Munich Germany

\section{Authors' contributions}

F.S., S.V., and M.D. had the idea. F.S. developed the prototype, drafted and revised the manuscript, and made the figure. On 27 March 2020, the employer informed F.S. that the decision to publish is up to him. The coauthors C.W. and E.H. gave medical advice, and revised and approved the manuscript. The collaborators S.V., M.D., and M.E. gave substantial medical advice. S.V., M.D., N.S., J.L., B.N., P.F., R.F., A.R., J.B., B.L., W.S., M.S., W.S., K.W., S.R., H.K., and E.H. assessed the prototype in a test track to simulate representative clinical scenarios. In addition, they were test models for the size dimensions, especially for the positioning of the passage openings. All of them gave practical and medical advice. All collaborators read and approved the manuscript. 


\section{Authors' information}

Not applicable.

\section{Funding}

Not applicable.

\section{Availability of data and materials}

1. Detailed description of the construction of the protection system: DOI https://doi.org/10.31219/osf.io/2s93d; https://osf.io/2s93d

2. Steam test videos: protection system with and without side shields DOI https://doi.org/10.17605/OSF.IO/7U2TV, Open Access Download: https:// osf.io/7u2tv

1 Protectionsystem no side shields lat view

2 Protectionsystem with side shields _ lat view

3 Protectionsystem no side shields _ frontal view

4 Protectionsystem with side shields _ frontal view

3. Information sheet in English and German language

DOl https://doi.org/10.17605/OSF.IO/7U2TV

Open Access Download: https://osf.io/7u2tv

\section{Ethics approval and consent to participate}

Not applicable.

\section{Consent for publication}

All individuals in the pictures of Fig. 1 gave written consent for publication. All the contributors and all person named in the "Acknowledgements" section gave written consent to have their name mentioned in this publication.

\section{Competing interests}

The authors declare that they have no competing interests.

\section{Author details}

'Department of Cardiology and Internal Intensive Care Medicine, Munich Clinic Bogenhausen, Academic Teaching Hospital, Technical University of Munich (TUM), Englschalkinger Str. 77, 81925 Munich, Germany. ${ }^{2}$ Department of Cardiology, Pneumology and Internal Intensive Care Medicine, Munich Clinic Schwabing, Academic Teaching Hospital, Ludwig-Maximilians-University (LMU), Munich, Germany. ${ }^{3}$ Department of Hematology, Oncology, Immunology, Palliative Medicine, Infectious Diseases and Tropical Medicine, Munich Clinic Schwabing, Academic Teaching Hospital (LMU), Kölner Platz 1, 80804 Munich, Germany.

\section{Received: 1 May 2020 Accepted: 11 May 2020}

Published online: 26 May 2020

\section{References}

1. Woelfel RC, Corman VM, Guggemos W, Seilmaier M, Zange S, Mueller MA, Niemeyer D, Jones Kelly TC, Vollmar P, Rothe C, Hoelscher M, Bleicker T, Bruenick S, Schneider J, Ehmann R, Zwirglmaier K, Drosten C, Wendtner C. Virological assessment of hospitalized cases of coronavirus disease 2019. Nature. 2020. https://doi.org/10.1038/s41586-020-2196-x.

2. Huang L, Lin G, Tang L, Yu L, Zhou Z. Special attention to nurses' protection during the COVID-19 epidemic. Crit Care. 2020;24(1):120.

3. Leonard S, Atwood CW Jr, Walsh BK, et al. Preliminary findings of control of dispersion of aerosols and droplets during high velocity nasal insufflation therapy using a simple surgical mask: implications for high flow nasal cannula. Chest. 2020. https://doi.org/10.1016/j.chest.2020.03.043.

4. Alhazzani W, Moller MH, Arabi YM, et al. Surviving sepsis campaign: guidelines on the management of critically ill adults with coronavirus disease 2019 (COVID-19). Crit Care Med. 2020. https://doi.org/10.1007/ s00134-020-06022-5.

5. Emanuel EJ, Persad G, Upshur R, et al. Fair allocation of scarce medical resources in the time of covid-19. N Engl J Med. 2020. https://doi.org/10 1056/NEJMsb2005114.

\section{Publisher's Note}

Springer Nature remains neutral with regard to jurisdictional claims in published maps and institutional affiliations. 